\title{
ANÁLISE DAS MANIFESTAÇÕES PATOLÓGICAS DOS REVESTIMENTOS DAS FACHADAS PRINCIPÁIS DA BIBLIOTECA PÚBLICA PELOTENSE
}

\author{
MARTINS, VANESSA PERES \\ Arquiteta e Urbanista, Mestranda \\ Faculdade de Arquitetura e Urbanismo (UFPEL) \\ Rio Grande do Sul; Brasil \\ vanessa_peresmartins@yahoo.com.br
}

\author{
ZSCHORNACK, RENATA BRAGA \\ Arquiteta e Urbanista \\ Universidade Católica de Pelotas (UCPEL) \\ Rio Grande do Sul; Brasil \\ renata_zschornack@hotmail.com
}

\author{
TORRES, ARIELA DA SILVA \\ Profa. Dra. Departamento de Tecnologia da Construção \\ Faculdade de Arquitetura e Urbanismo (UFPEL) \\ Rio Grande do Sul; Brasil \\ arielatorres@gmail.com
}

\section{RESUMO}

Pelotas, no Rio Grande do Sul, possui um dos maiores acervos de estilo eclético do país (IPHAN), um exemplar disto é a Biblioteca Pública Pelotense (BPP). A conservação das edificações históricas é importante para a cidade. O objetivo deste trabalho é identificar as principais manifestações patológicas presentes nas fachadas da BPP e sugerir soluções para sua conservação. Assim, o trabalho desenvolveu-se em quatro etapas: pesquisa bibliográfica, levantamento de subsídios e registros fotográficos, mapeamento e identificação das manifestações patológicas. Como resultado, destacaram-se: sujidade, manchas de mofo e bolor e descolamento de revestimento. Observou-se que os danos mais significativos resultam da forma de interação dos usuários do espaço público com a edificação e que, por consequência, a conservação destas fachadas, além das soluções técnico-construtivas, deve apresentar soluções que busquem melhorar a relação do usuário do espaço com a edificação.

Palavras-chave: Manifestações patológicas, Patrimônio histórico; Conservação.

\section{ABSTRACT}

Pelotas, in Rio Grande do Sul, has one of the largest collections of eclectic style in the country (IPHAN), an example of this is the Pelotense Public Library (PPL). The conservation of historic buildings is important to the city. The objective of this paper is to identify the main pathological manifestations present in the facades of PPL and to suggest solutions for their conservation. Thus, the work developed four stages: bibliographic research, gathering of subsidies and photographic records, mapping and identification of pathological manifestations. As a result, the following stood out: dirt, mold and mildew stains and coating detachment. It was observed that the most significant damages result from the interaction between the users of the public space and the building and, consequently, the conservation of these facades, in addition to the technical-constructive solutions, should present solutions that seek to improve the relationship user and building.

Keywords: Pathological manifestations, Historical heritage; Conservation.

\section{INTRODUÇÃO}

A cidade de Pelotas, localizada no sul do Rio Grande do Sul, tem como principal característica o seu patrimônio histórico. Segundo o Instituto do Patrimônio Histórico e Artístico Nacional (IPHAN) a cidade possui um dos maiores acervos de estilo eclético do país, sendo um exemplo deste acervo o prédio da Biblioteca Pública Pelotense. Este prédio histórico, assim como muitos outros prédios históricos das cidades brasileiras, apresenta no revestimento externo das suas fachadas a presença de manifestações patológicas. Os revestimentos externos das edificações funcionam como uma primeira camada de proteção, atuando principalmente na preservação da edificação frente aos efeitos dos agentes ambientais, esta camada de proteção apresenta menor vida útil quando comparada com a estrutura da edificação (SILVA et al.,2011). 
As manifestações patológicas em revestimentos de edificações têm sido estudadas e discutidas em trabalhos como o de Antunes (2010) que estuda as manifestações patológicas em revestimento de fachada em Brasília/DF, Terra (2001) por sua vez aborda as manifestações patológicas em revestimentos de fachadas de edificações da cidade de Pelotas/RS e Peres (2001) que desenvolve o levantamento e identificação de manifestações patológicas presentes em edificação histórica localizada na cidade de Pelotas/RS.

A importância dos revestimentos de fachadas é ainda maior quando considerados os prédios históricos, pois, conforme Kühl (2004), além atuarem na proteção da edificação contra fatores do ambiente externo, estas camadas de revestimento são também testemunho da história da edificação, adquirindo valores plásticos e simbólicos relacionados com as marcas da passagem do tempo. Segundo Peres (2001), as intervenções em edificações históricas têm que considerar uma restrição a mais que as edificações antigas em geral, tal restrição está associada com a manutenção do valor histórico da edificação. Neste sentido, conforme Peres (2001), quando a preservação do valor histórico da edificação é realizada a por meio da preservação do existente, tal opção pode ocasionar o agravamento das manifestações patológicas, principalmente daquelas originadas pela falta de manutenção da edificação. Por outro lado, se a intervenção na edificação histórica seguir outra abordagem teórica da restauração como, por exemplo, a que entende a camada de superfície externa da edificação como camada de "sacrifício", que deve ser renovada periodicamente, objetivando a proteção da edificação, passamos à discussão relacionada a perda do registro histórico e dos sinais deixados pela passagem do tempo. Portanto, diante da complexidade das questões que envolvem as intervenções em edificações históricas, Kühl (2004) salienta que as decisões relativas ao tratamento das camadas de revestimento externo das edificações históricas sejam realizadas a partir de juízo histórico crítico, entendendo e analisando os aspecto positivos e negativos resultantes da ação do tempo.

Em pesquisa realizada com o objetivo de verificar as manifestações patológicas presentes em edificações ecléticas localizadas na área central de Pelotas Oliveira e Azevedo (1994) apud Peres (2001) apontaram que 60,34\% das edificações apresentavam falta de manutenção, 20,66\% apresentavam erro de projeto e 19,00\% possuíam materiais inadequados. A análise das manifestações patológicas presentes em edificações tem como finalidade tanto a solução do problema em si, como também possibilita a identificação da origem das patologias, atuando no sentido de evitar a recorrência de danos.

Assim, entendo a importância que as fachadas têm para a comunicação estética das edificações e que a falta de periodicidade na manutenção das camadas de revestimento, além de agravar as patologias e gerar danos com maior custo para de solução, desvaloriza e compromete a legibilidade da edificação histórica. Este artigo tem como objetivo identificar as principais manifestações patológicas presentes nas fachadas da Biblioteca Pública Pelotense (BPP) e sugerir soluções para sua conservação. Assim, o trabalho desenvolveu-se em quatro etapas: pesquisa bibliográfica, levantamento de subsídios e registros fotográficos, mapeamento e identificação das manifestações patológicas. A metodologia utilizada é uma adaptação da metodologia proposta por Lichtenstein (1986). Por meio do levantamento realizado nas fachadas da BPP busca-se analisar a incidência de manifestações patológicas e documentar o estado atual das fachadas, contribuindo desta maneira com subsídios para futuras investigações.

\section{CARACTERIZAÇÃO DO OBJETO DE ESTUDO}

A arquitetura eclética de Pelotas, edificada no final do século XIX e início do século XX, tem relação com o apogeu econômico vivenciado pela cidade no período em que a sua atividade econômica era ligada a produção de charque (DALTOÉ, 2013). Um exemplar da arquitetura deste período é o prédio da Biblioteca Pública Pelotense, que teve a sua construção iniciada em 1881 e concluída em 1888, com projeto de José Izella que contemplava apenas um piso térreo (CHEVALIER, 2002). Em 1915, devido a necessidade de mais espaço, foram inauguradas as obras de ampliação do segundo pavimento da Biblioteca, projeto de Caetano Casaretto. O prédio da Biblioteca Pública Pelotense passou por algumas intervenções de recuperação no seu período de existência, entre elas a realizada em 2005, para a recuperação da clarabóia central que desabou parcialmente (BIBLIOTECA). Além dos livros e periódicos, comuns às bibliotecas em geral, a BPP tem instalado no porão do prédio um Museu, com objetos e peças que contam um pouco da história da cidade e abriga também algumas exposições temáticas.

O Conjunto Histórico de Pelotas foi tombado em nível federal, em 2018, pelo IPHAN, no projeto apresentado e aprovado pelo conselho consultivo do IPHAN, em Brasília, foi proposta a preservação integral do prédio da Biblioteca Pública Pelotense juntamente com o setor da Praça Coronel Pedro Osório (IPHAN, 2018). Este setor, segundo Rodrighiero (2019) é composto tanto por edificações inventariadas a nível municipal, quanto por edificações tombadas nos diferentes níveis, federal, estadual ou municipal (Figura 1). 

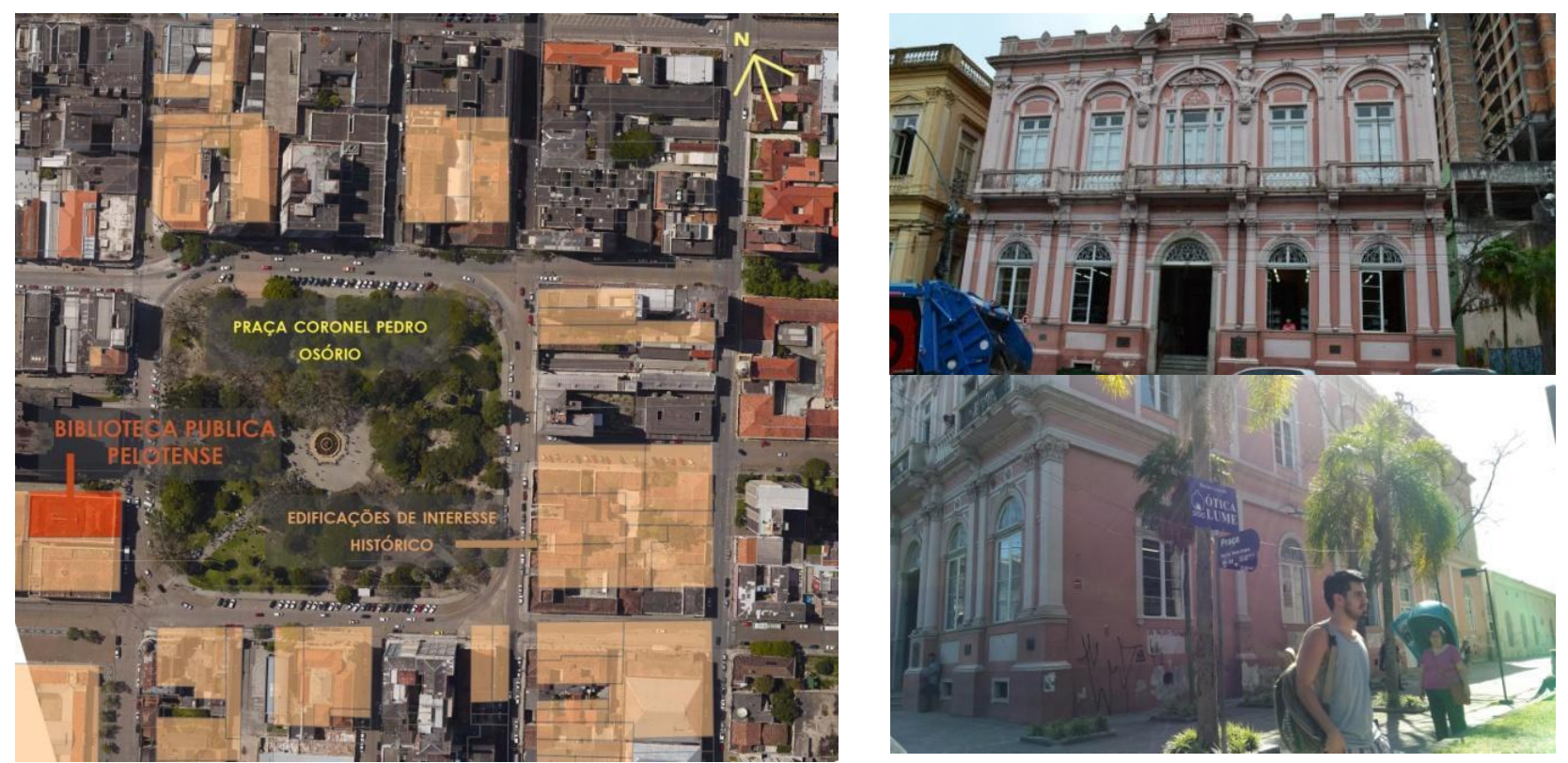

Figura 1: Localização e fotos da Biblioteca Pública Pelotense. Fonte: Autoras

\section{METODOLOGIA}

Para atingir o objetivo do trabalho foram realizadas as seguintes etapas: pesquisa bibliográfica, levantamento de subsídios e registros fotográficos, mapeamento e identificação das manifestações patológicas encontradas nas fachadas da BPP tendo como base a metodologia proposta por Lichtenstein (1986). O levantamento de subsídios e registros fotográficos foram realizados a partir da análise visual do prédio, efetuada em novembro de 2018. O registro das manifestações patológicas encontradas foi realizado por meio da fotografia (Figura 2), como instrumento para os registros fotográficos foi utilizada a câmera Nikon D3100.
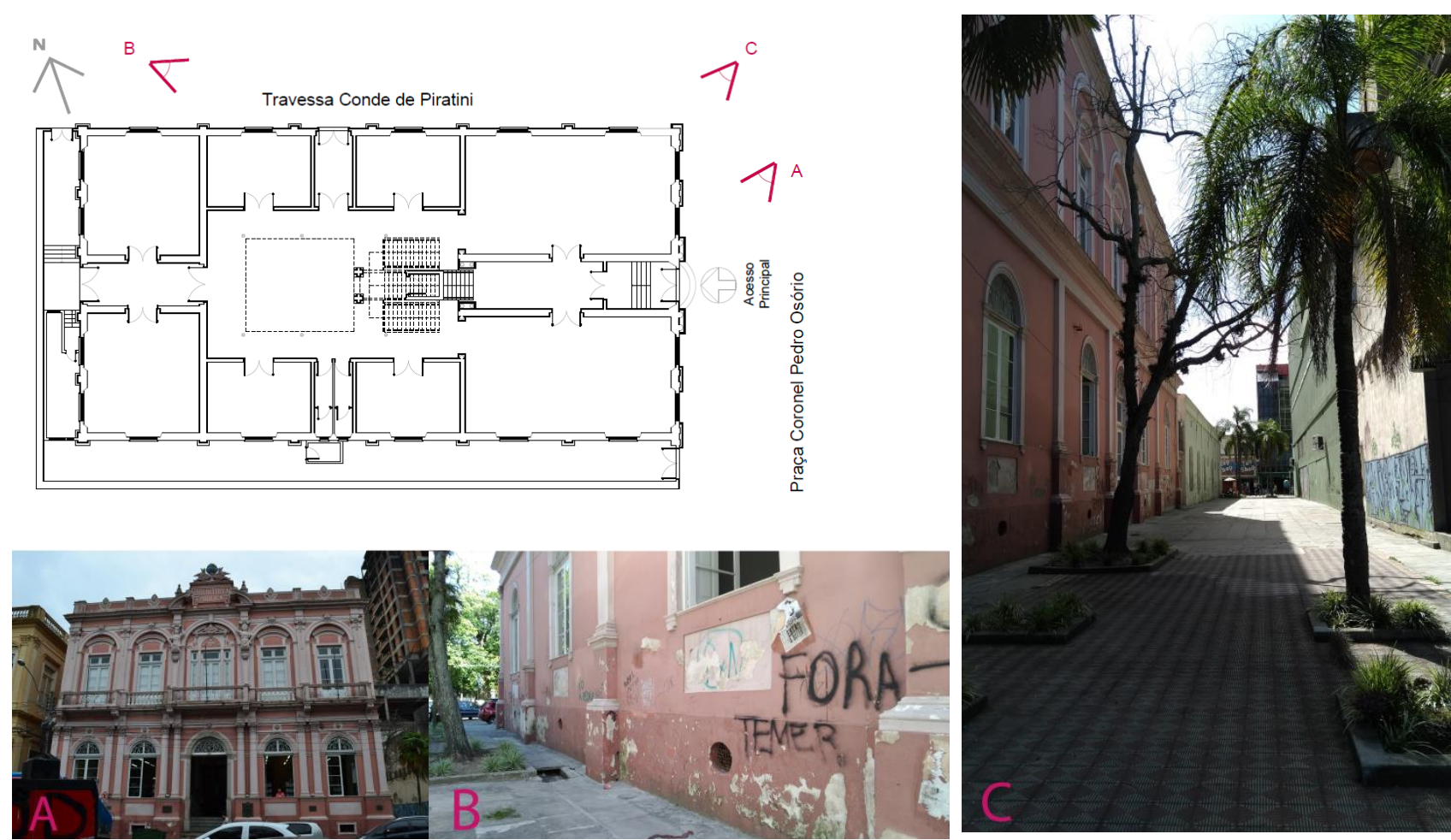

Figura 2: Levantamento fotográfico da Biblioteca Pública Pelotense. Fonte: Desenho acervo da SECULT, modificado pelas Autoras. 
O mapeamento das manifestações patológicas foi realizado a partir do desenho no software Autocad ® tendo como base as fotografias das fachadas. Com este objetivo foi elaborada uma legenda para identificação das manifestações e após o desenho, foi calculada a área de incidência de cada tipologia de manifestação patológica e desenvolvida a relação da área afetada com a área total de cada fachada analisada.

\section{RESULTADOS E DISCUSSÕES}

Como resultado das análises das manifestações patológicas mapeadas nas fachadas principais da Biblioteca Pública Pelotense destacaram-se respectivamente as manifestações patológicas como: sujidade, manchas de mofo e bolor e descolamento de revestimento. As manifestações patológicas presentes nas fachadas da Biblioteca Pública Pelotense tem relação com fatores como intempéries, fatores biológicos e mecânicos. Porém os danos mais graves estão relacionados com a forma de interação dos usuários do espaço público com a edificação histórica.

\subsection{Mapeamento das manifestações patológicas}

Para mapeamento das manifestações patológicas presentes na fachadas da BPP, foi utlizada a legenda (Figura 3) em que estão listadas tipologias de manifestações patológicas.

FISSURAS, TRINCAS, RACHADURAS EFLORESCENCIA DESCOLAMENTO DE REVESTIMENTO
DESCOLAMENTO DA PINTURA MANCHAS DE MOFO, BOLOR MANCHAS DE UMIDADE
DETERIORAÇĀO DA MADEIRA

Figura 3: Legendas de análise das Manifestações Patológicas. Fonte: Autoras

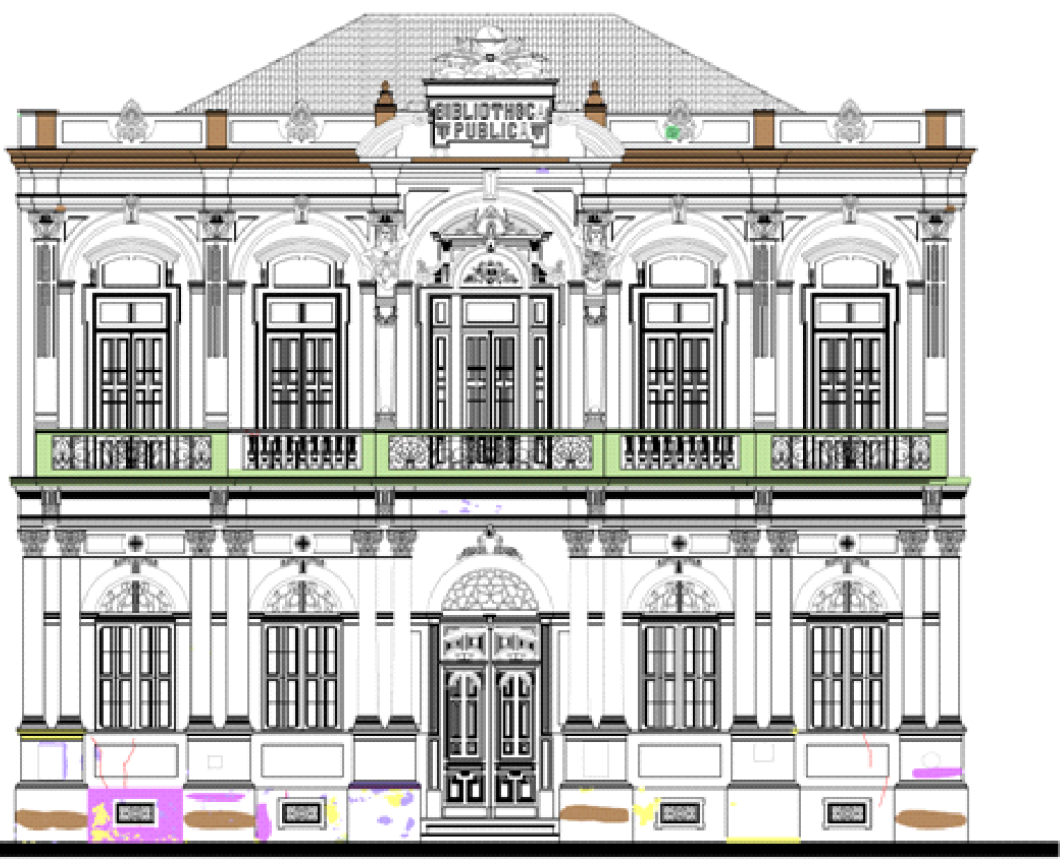

Figura 4: Fachada Sudeste da Biblioteca Pública Pelotense. Análise de Manifestações Patológicas. Fonte: Desenhos acervo da SECULT, modificados pelas autoras.

A fachada sudeste, por onde se dá o acesso principal à edificação, fica voltada para a Praça Coronel Pedro Osório, as principais manifestações patológicas observadas como manchas de mofo e sujidades estão localizadas nos elementos avançados da fachada, que atuam na proteção dos panos das paredes. A base da edificação também apresenta concentração de manifestações patológicas como sujidade, descolamento de revestimento e pintura (Figura 4). 


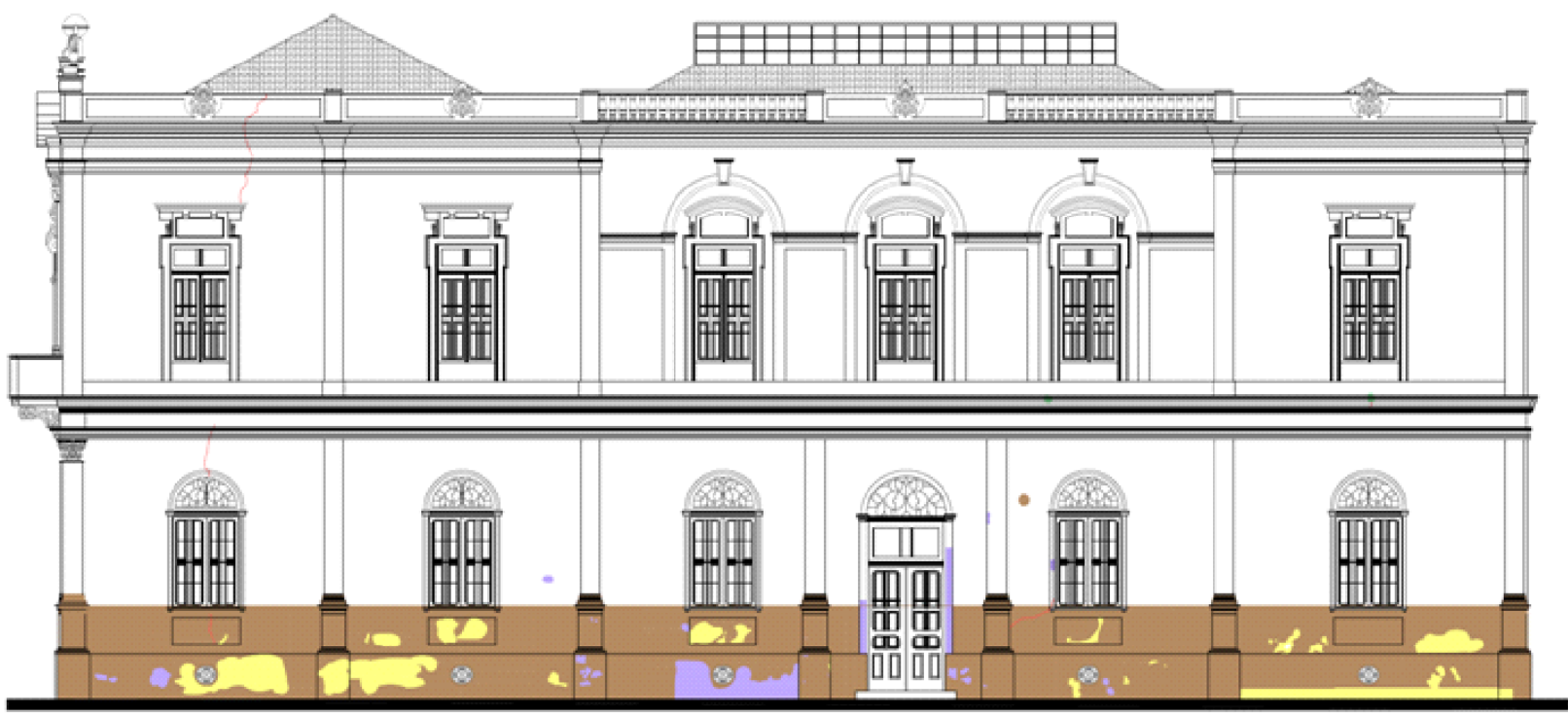

Figura 5: Fachada Nordeste da Biblioteca Pública Pelotense. Análise de Manifestações Patológicas. Fonte: Desenhos acervo da SECULT, modificados pelas autoras.

A análise da fachada nordeste da edificação junto à Travessa Conde de Piratini, apresenta uma grande incidência de sujidade, principalmente na faixa que que tem inicio na base da edificação até aproximadamente 2,40m de altura, na qual são recorrentes as pichações e a fixação cartazes, as outras manifestações que foram observadas nestas fachada foram o descolamento de revestimento e o descolamento de pintura. A inicidência e localização das sujidades nesta fachada indica para uma possível contribuição do ambiente urbano, pois a travessa em que está localizada esta fachada, é pouco movimentada e poussui na sua extensão muitas fachadas cegas, fatores que tornam o local um ambiente favorável para ações danosas como a pichação e, muito mais grave, a transformam em um mictório público, o que pode vir a contribuir também com o descolamento de revestimento em algumas áreas da fachada (Figura 5).

\subsection{Identificação das principais patologias}

As manifestações patológicas identificadas com maior incidência, após a aplicação de metodologia, na fachada principal da BPP: manchas de mofo e bolor com 4,1\%, seguido por sujidades 3,2\% e empolamento com $0,7 \%$, já para a fachada lateral da BPP a maior incidência foi de 10,9\% de sujidade, 1,3\% de descolamento de revestimento e 0,6\% de descolamento de pintura (Figura 6).

Manifestações Patológicas - Fachada Principal

Manifestações Patológicas - Fachada Lateral

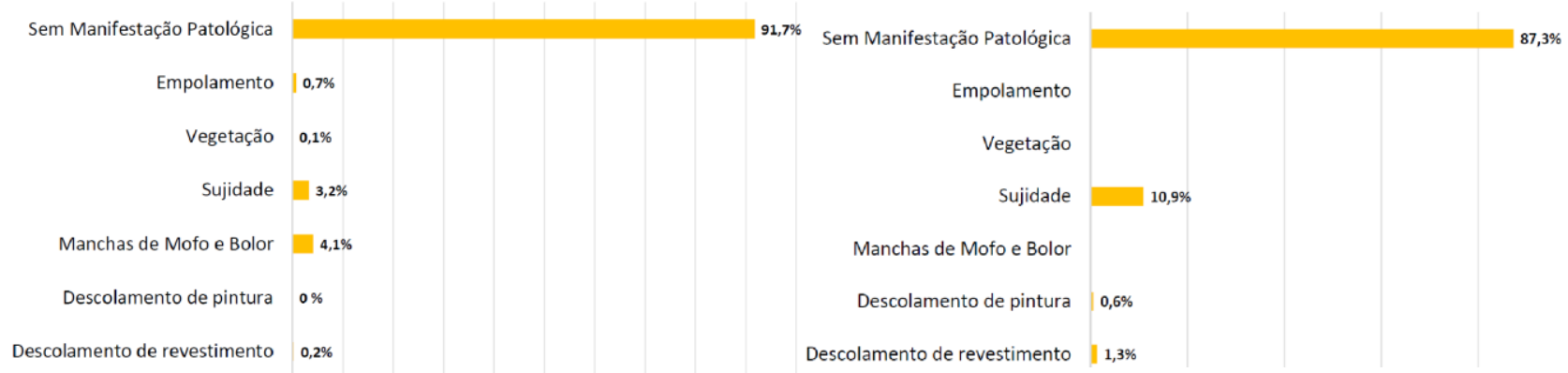

Figura 6: Gráfico das Manifestações patológicas da Biblioteca Pública Pelotense. Fonte: As autoras

Os resultados totais obtidos pela análise conjunta das manifestações patológicas das fachadas da BPP, indicam como manifestações mais incidentes a sujidade $14,1 \%$, as manchas de mofo e bolor $4,1 \%$ e o descolamento de revestimento $1,5 \%$, seguidos por empolamento $0,7 \%$ e descolamento de pintura $0,6 \%$. A partir desta análise das tipologias de manifestações patológicas presentes nas fachadas da BPP foi possível observar que os dados obtidos corroboram com os dados do trabalho de Oliveira e Azevedo (1994) apud Peres (2001), o qual aponta que 74\% das construções ecléticas 
da área central de Pelotas analisadas apresentaram bolor; $20 \%$ empolamento; 3,44\% apresentaram eflorescência e 2,5\% apresentaram outros problemas.

A análise dos dados sugere também a necessidade de proporcionar uma melhor relação do usuário do espaço público com a edificação histórica a fim de evitar a recorrência de danos às fachadas. Visto que a sujidade, manifestação que tem maior incidência no total das patologias identificadas, têm maior ocorrência na fachada lateral da edificação, desenvolvendo-se em uma faixa de 2,40m de altura, na qual são recorrentes as pichações e a fixação de cartazes. Assim, por meio da visita realizada a edificação, observou-se que contribuem para as ações danosas às camadas de revestimento da BPP a forma de interação dos usuários do espaço público com a edificação. Apesar da Biblioteca Pública Pelotense se encontrar na área central da cidade, região abastecida de serviços e comércio e que conta com grande circulação de pessoas, a Travessa Conde de Piratini, exclusiva para circulação de pedestres, não é utilizada pelos usuários que se deslocam nesta área, pois, não se sentem seguras. Contribuem para esta sensação de insegurança, a altura das edificações que fazem limite com a Travessa, a Biblioteca com aproximadamente $6 \mathrm{~m}$ e a edificação vizinha com aproximadamente $9 \mathrm{~m}$, a falta de aberturas e de fachadas voltadas para esse local - as fachadas quando existem são em sua maioria, paredes cegas-, tal configuração além de provocar a sensação de insegurança, propicia as ações de degradação das edificações, sejam elas por meio de pichações ou pelo uso do local como mictório público. Neste sentido, além das soluções técnico-construtivas para a preservação das fachadas da BPP, seriam necessárias também as ações de intervenção na qualidade desta Travessa, criando a partir da requalificação deste espaço um ambiente agradável e seguro para tanto para a circulação e quanto para a contemplação da área e da edificação histórica.

\section{CONCLUSÃO}

O trabalho com edificações antigas se relaciona com a presença, quase que intrínseca, de manifestações patológicas. São muitos os fatores que contribuem para este tipo de situação, agentes de natureza mecânica, eletromagnética, térmica, química ou biológica.

Os trabalhos de mapeamento das manifestações patológicas contribuem para a documentação do estado atual das edificações e proporcionam meios para a realização de análise da recorrência ou não de manifestações específicas nos mesmos pontos, possibilitando que as soluções de intervenção também sejam ajustadas, da mais superficial para a mais agressiva.

No caso das manifestações patológicas presentes nas fachadas da Bibliotheca Pública Pelotense, uma abordagem para a intervenção nas patologias identificadas, engloba, além das soluções técnico-construtivas realizadas na própria edificação, as relacionadas com a requalificação da área onde está inserida a edificação, a fim de transformar a relação entre os usuários do espaço público e a edificação.

\section{REFERÊNCIAS}

ANTUNES, R. G. Estudo de manifestações patológicas em revestimento de fachada em Brasília - sistematização da incidência de casos/DF. Dissertação (Mestrado) - Universidade de Brasília, Departamento de Engenharia Civil e Ambiental. Brasília, 2010.

BIBLIOTECA. História. Disponível em: <http://http://www.bibliotheca.org.br/historia/>. Acesso em: 18 de dez. 2019.

CHEVALIER, Ceres. Vida e obra de José Isella: arquitetura em Pelotas na segunda metade do século XIX. Dissertação - Universidade Federal do Rio Grande do Sul, 2002.

DALTOÉ, Guilherme. Arquitetura Eclética de Caetano Casaretto em Pelotas/RS. Revista Memória em Rede, Pelotas, v.3, n.8, Jan./Jun.2013 - ISSN- 2177-4129.

IPHAN. Ata 88. http://portal.iphan.gov.br/uploads/atas/88_reuniao_ordinaria_do_conselho_consultivo.pdf Acesso em: 18 de dez. 2019.

IPHAN. Pelotas (RS). Disponível em: <http://portal.iphan.gov.br/pagina/detalhes/281>. Acesso em: 15 de dez. 2019.

LiChtenstein, N. B. Patologia das Construções. Boletim Técnico 06/86. Escola Politécnica da Universidade de São Paulo. Departamento de Engenharia e Construção Civil. São Paulo, 1986. 


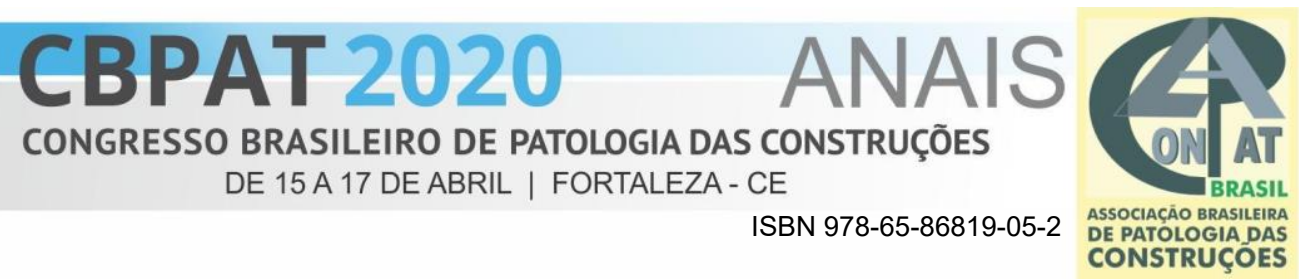

OLIVEIRA, A. L. C.; AZEVEDO, S. L. Estudos de Casos Patológicos Relativos à Umidade em Construções Ecléticas da Área Central de Pelotas. Relatório PET/Arquitetura. Pelotas:UFPEL, 1994.

PERES, R. M. Levantamento e Identificação da Manifestações patológicas em Prédios Históricos - Um estudo de caso. Dissertação (Mestrado) - PPGE/Universidade Federal do Rio Grande do Sul, Porto Alegre. 2001.

RODRIGHIERO, J.; OLIVEIRA, A. L. C. Descaracterização no ecletismo: conceitos e método de avaliação. Risco Revista De Pesquisa Em Arquitetura E Urbanismo (Online), 17(3), 145-163. https://doi.org/10.11606/issn.19844506.v17i3p145-163, 2019. Acesso em: 19 de dez. 2019.

SILVA, A.; BRITO, J. de; GASPAR, P. L;. Service life prediction model applied to natural stone wall claddings (directly adhered to the substrate). Construction and Building Materials. Elsevier, 2011. 